\title{
Performance de crianças falantes do Português Brasileiro no Test of Early Language Development (TELD-3)
}

\author{
Elisabete Giusti ${ }^{1}$
}

Giusti E. Performance de crianças típicas falantes do Português Brasileiro no Test of Early Language Development (TELD-3) [tese]. São Paulo: Universidade de São Paulo, 2007.

Para avaliar a aquisição e o desenvolvimento da linguagem na infância, diversos procedimentos são indicados. Apesar da diversidade encontrada, alguns pesquisadores da área são unânimes em afirmar a necessidade de usar testes formais e objetivos. No Brasil, faltam testes para esta finalidade. O objetivo geral desta Tese foi verificar a performance de crianças típicas falantes do Português Brasileiro no Test of Early Language Development -3 (TELD-3, de Hresko, Reid e Hammill, 1999). Participaram deste estudo 120 crianças, com faixa etária entre 2:00 anos e 7:11 anos, sendo 20 sujeitos por faixa etária (10 do sexo masculino e 10 do sexo feminino). Esta tese foi dividida em três estudos. No Estudo I foi apresentada a tradução do TELD-3 para o Português Brasileiro e os resultados obtidos indicaram que os procedimentos adotados na tradução do referido teste mantiveram sua equivalência com a versão original, indicando que não houve mudanças significativas no conteúdo e formato do teste, aspecto importante em pesquisas deste tipo. No Estudo II foi analisada a performance dos sujeitos típicos falantes do Português Brasileiro no teste. Os resultados indicaram que a performance foi compatível com a média esperada para to- das as faixas etárias, exceto para o grupo de sujeitos de cinco e seis anos, no subteste expressivo da forma B, que foram classificados como "abaixo da média". Além disso, observouse que as formas A e B do teste não foram equivalentes para todas as faixas etárias e houve um aumento nos valores dos escores brutos com o aumento da idade cronológica. No Estudo III foi realizada uma análise comparativa entre a performance dos sujeitos falantes do Português (Brasil) e os sujeitos falantes do Inglês (EUA) no referido Teste. Os resultados indicaram que a performance dos dois grupos de sujeitos foi equivalente até 4:11 anos. Os sujeitos de cinco, seis e sete anos, falantes do Português obtiveram pontuação mais alta no subteste receptivo da Forma A e o no subteste expressivo da Forma B, os sujeitos de cinco e seisanos obtiveram pontuação mais baixa do que os sujeitos falantes do Inglês.

Como conclusão, os resultados dos estudos apresentados parecem indicar que a versão traduzida para o Português Brasileiro do TELD-3 mostrou-se sensível para caracterizar a performance de linguagem da população estudada. Futuras pesquisas relacionadas à sensibilidade e especificidade do teste são necessárias.

(1) Doutora em Semiótica e Linguística Geral pela Faculdade de Filosofia, Letras e Ciências Humanas da Universidade de São Paulo - USP - São Paulo (SP), Brasil; Coordenadora da Equipe de Diagnóstico da Associação de Pais e Amigos dos Excepcionais de Limeira - APAE - Limeira (SP), Brasil

Tese apresentada à Faculdade de Filosofia, Letras e Ciências Humanas da Universidade de São Paulo - USP - São Paulo (SP), Brasil, para obtenção do título de Doutor em Lingüística, área de concentração Semiótica e Lingüística Geral, sob orientação da Profa. Dra. Debora Maria Befi-Lopes.

Endereço para correspondência: Elisabete Giusti. Av. Cônego Manuel Alves, 782, Limeira - SP, CEP 13484-420. E-mail: e.giusti@uol.com.br 